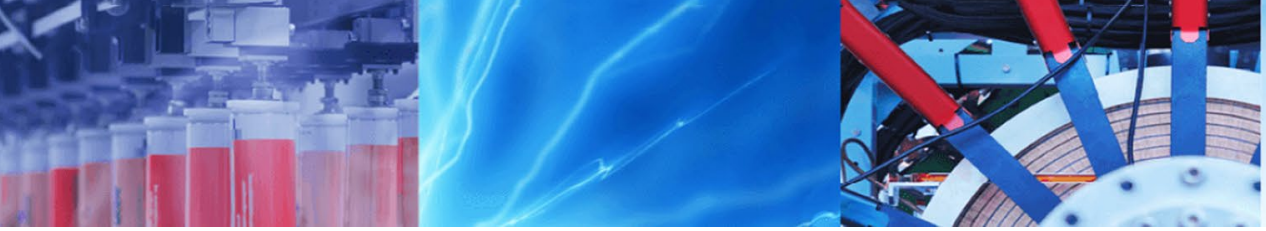

Research Article

\title{
Characterization of flame coated nanoparticle surfaces with antibacterial properties and the heat-induced embedding in thermoplastic-coated paper
}

\author{
Kofi J. Brobbey ${ }^{1}$ (I) Janne Haapanen ${ }^{2} \cdot$ Jyrki M. Mäkelä $^{2} \cdot$ Marianne Gunell $^{3,6} \cdot$ Erkki Eerola $^{3,6} \cdot$ Emil Rosqvist $^{4}$. \\ Jouko Peltonen ${ }^{4}$. Jarkko J. Saarinen ${ }^{5}$ - Martti Toivakka ${ }^{1}$
}

(C) The Author(s) 2018 OPEN

\begin{abstract}
Silver nanoparticles deposited on surfaces can provide an antibacterial effect with potential uses in, for example, healthcare settings. However, release of nanoparticles and their potential exposure to the environment is of concern. The current work demonstrates a continuous synthesis that simultaneously deposits silver nanoparticles onto plastic coated paper surface by utilizing the liquid flame spray (LFS) aerosol process. Heat from LFS is used to soften the thermoplastic paper surface, which enables partial and full embedding of the nanoparticles, thereby improving adhesion. The embedding is confirmed with atomic force and scanning electron microscopy, and the deposited silver amounts are quantified with $\mathrm{X}$-ray photoelectron spectroscopy. The results suggest that embedding was more effective in PE-coated paper samples due to the lower glass transition temperature when compared to PET-coated paper samples. The antibacterial properties of the surfaces against E. coli and S. aureus were maintained and confirmed with a previously developed 'TouchTest Method'. The LFS process has the potential to be used for large-scale manufacturing of antibacterial surfaces with improved nanoparticle adhesion on appropriately chosen thermoplastic surfaces.
\end{abstract}

Keywords Liquid flame spray (LFS) · Silver nanoparticles · Heat-induced embedding · Antibacterial effects · PE/PET coatings · AFM stiffness measurement

\section{Introduction}

The fight against pathogenic bacteria has resulted in an increased use of antimicrobial agents over the years [9, $11,17,36,37]$. These antimicrobial agents, which include antibacterial nanoparticles, have made it possible to effectively control pathogenic bacteria, especially when used together with other existing methods such as antibiotics $[5,28]$. As a result, the significance of nanoparticles cannot be disregarded since they have also shown promise against drug resistant bacteria [1]. Nanoparticles are widely used in different products due to superior properties as compared to the bulk material $[6,7,20]$. Silver nanoparticles have been extensively studied, and they have been used in several applications, including antibacterial products and fuel cells $[29,31]$. Although the use of silver nanoparticles has shown positive results against pathogenic bacteria, there are concerns about nanoparticle exposure to the environment, largely due to reports of cytotoxic effects $[14,15,32,38,44]$. Inadequate

Kofi J. Brobbey, kofi.brobbey@abo.fi| 'Laboratory of Paper Coating and Converting, Center for Functional Materials, Åbo Akademi University, Porthaninkatu 3, 20500 Turku, Finland. ${ }^{2}$ Aerosol Physics, Faculty of Natural Sciences, Tampere University of Technology, P.O. Box 692, 33101 Tampere, Finland. ${ }^{3}$ Medical Microbiology and Immunology, University of Turku, Kiinamyllynkatu 10, 20520 Turku, Finland. ${ }^{4}$ Laboratory of Physical Chemistry, Åbo Akademi University, Porthansgatan 3, 20500 Turku, Finland. ${ }^{5}$ Department of Chemistry, University of Eastern Finland, P.O. Box 111, 80101 Joensuu, Finland. ${ }^{6}$ Clinical Microbiology Department, Laboratory Division, Turku University Hospital, Kiinamyllynkatu 13, 20520 Turku, Finland. 
information about the fate of silver nanoparticles in the environment has often been an obstacle for their use in different products $[14,25,40]$.

There have been numerous attempts that have focused on embedding or immobilizing nanoparticles within a material matrix, in order to limit environmental exposure $[12,24,27,30,43]$. However, silver nanoparticles typically require a direct path of action. For example, antibacterial effects may require porous substrates that allow release and percolation of silver ions $[13,22]$. Alternatively, the matrix should be such that silver can be released through it over time [41]. Other alternatives that have been considered include chemical grafting of particles to the substrate surface $[35,39]$. Immobilizing nanoparticles onto a surface presents a unique advantage of having particles available for antibacterial activity while limiting their environmental exposure $[8,42]$. The synthesis technique used and substrate properties may also dictate the mode of incorporating particles into the sample $[8,16]$, for instance, paper samples may experience wet breaks when embedding of nanoparticles is done by immersing into a solution containing silver nanoparticles.

Liquid flame spray (LFS) is an aerosol technique that can be used to simultaneously produce and deposit nanoparticles onto different substrates in a continuous roll-to-roll process at speeds up to and beyond $300 \mathrm{~m} / \mathrm{min}[2,23,33$, 34]. A one-step flame synthesis of antibacterial paper using LFS has recently been demonstrated [3]. While antibacterial effect against both gram-negative and gram-positive bacteria was demonstrated, poor adhesion of the nanoparticles onto the paper surface provided by weak Van der Waal forces is of concern. Therefore, the current study aims specifically at improving the nanoparticle adhesion. Heat produced during LFS coating can be used to promote thermo-mechanical adherence of nanoparticles, especially if the surface to be coated is thermoplastic. The improved adhesion can limit environmental exposure of nanoparticles while maintaining the desired antibacterial effect. Paper precoated with polyethylene and polyethylene terephthalate (PE \& PET) were used as substrates. Silver nanoparticles were deposited onto these samples using LFS. X-ray photoelectron spectroscopy (XPS), scanning electron microscopy (SEM), and atomic force microscopy (AFM) were used as surface characterization techniques.

\section{Materials and methods}

\subsection{LFS coatings}

Silver nitrate $\left(\mathrm{AgNO}_{3}, 99.9+\%\right.$, Alfa Aesar) with Ag concentration of $250 \mathrm{mg} / \mathrm{mL}$ was dissolved in deionized water and used as a precursor solution. The precursor was delivered through a nozzle and atomized using a high temperature hydrogen, oxygen and nitrogen flame. Decomposition and nucleation occurs in the presence of the flame, resulting in the formation of silver nanoparticles. The used gas flow rate $\left(\mathrm{H}_{2} / \mathrm{O}_{2} / \mathrm{N}_{2}\right)$ and the precursor feed rate were $20 / 10 / 5 \mathrm{l} /$ min and $2 \mathrm{ml} / \mathrm{min}$, respectively. Further description of the LFS process is given in previous studies $[18,19]$. The flame producing the nanoparticles was directed towards the substrate surface. The paper samples were attached to a sample holder that rotated across the flame resulting in nanoparticle deposition onto the surface. The nozzle was placed $20 \mathrm{~cm}$ away from the sample surface. The setup for LFS deposition is shown in Fig. 1. Silver nanoparticles were deposited onto PE and PET extrusion coated paper surfaces using the LFS. The nanoparticle deposition amount was controlled by the number of times the samples were passed across the flame resulting in an increasing amount

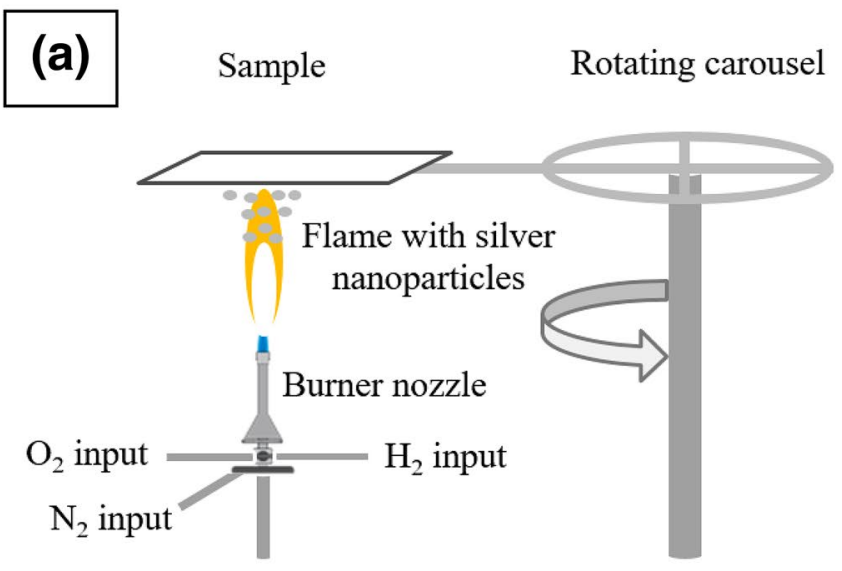

$\mathrm{AgNO}_{3}$ precursor

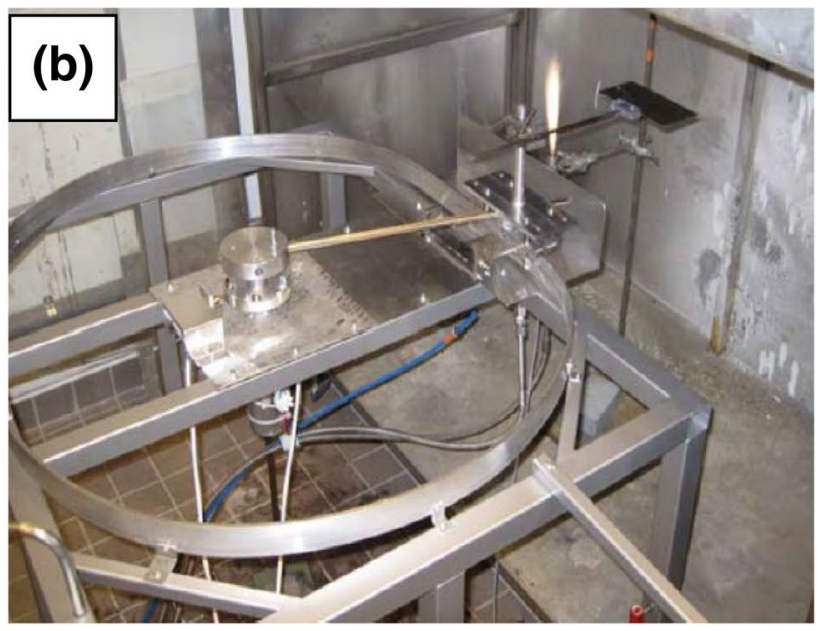

Fig. 1 A schematic of the LFS process used to deposit silver nanoparticles on glass surface in (a) and an image of the setup in (b) 
of deposited nanoparticles. The samples are labeled $1 \mathrm{X}$, $3 \mathrm{X}, 5 \mathrm{X}, 10 \mathrm{X}$ and $30 \mathrm{X}$, corresponding to the number of passes through the flame, and with PE or PET prefix to signify the type of polymer coating.

\subsection{Scanning electron microscopy (SEM) surface imaging}

The coated sample surfaces were visualized using a LEO Gemini 1530 SEM from Carl Zeiss, Germany. Before imaging, the samples were sputtered with a carbon coating to reduce accumulation of surface charge. The accelerating voltage was $2.7 \mathrm{kV}$ with a magnification of up to $100 \mathrm{kX}$ at a working distance of $4 \mathrm{~mm}$.

\subsection{Cross-sectional imaging}

A dual beam FIB-SEM (FEl Helios Nanolab 600) was used to cut and image sample cross-sections of the nanoparticlecoated samples. Samples were precoated with a thin strip of platinum, and cut using a gallium ion beam. During the SEM imaging, samples were tilted at an angle to show both the perpendicular surface image and the cross-section of the sample.

\subsection{Atomic force microscopy (AFM)}

Topographical imaging of the surfaces was conducted with Bruker's Nanoscope V MultiMode 8 AFM. Images of the size $2 \mu \mathrm{m}$ by $2 \mu \mathrm{m}$ with a resolution of 1024 by 1024 pixels were captured at a scan speed of 0.5-1 lines per second. Silicon cantilevers with average tip radius of $8 \mathrm{~nm}$ (NSG10, NT-MDT, Russia) and a deflection sensitivity of 31.4-57.4 nm/V (average $40.9 \mathrm{~nm} / \mathrm{V}$ ) were used. Both conventional tapping mode and PeakForce modes were used for imaging. The free amplitude was set to $500 \mathrm{mV}$ for soft tapping corresponding to a free amplitude $\left(A_{0}\right)$ of $10-15 \mathrm{~nm}$, or $1500 \mathrm{mV}$ for a harder tapping $\left(A_{0}=30-45 \mathrm{~nm}\right)$. Image processing techniques such as the third order polynomial fit and plane leveling were used prior to analyzing the data. Topography, stiffness maps and phase images were measured to differentiate between nanoparticles and the polymer. Stiffness and phase images gave information about the mechanical properties, and the results were analyzed in comparison to the height images from the same location on the sample surface.

\subsection{X-ray photoelectron spectroscopy (XPS) measurements of silver}

Surface chemical composition was determined using XPS (PHI Quantum 2000 from Physical Electronics Instruments, USA), and the corresponding peaks in the spectra were used for chemical identification with reference to standard peaks of elements [21]. XPS measurements provided a semi-quantitative determination of chemical amounts in atomic percentage relative to the total atomic composition of the surface. A monoenergetic Al source was used as the source of $\mathrm{X}$-rays. The irradiation aperture of was $200 \mu \mathrm{m}$ with a pass energy of $117.4 \mathrm{eV}$. Each sample was measured at three different locations on the surface and the average was calculated. Multipack software was used to analyze the XPS data using reference carbon at a peak location of $284.5 \mathrm{eV}$.

\subsection{Antibacterial testing}

Antibacterial properties of coated samples were tested against Gram-negative Escherichia coli (E. coli, ATCC 25922) and Gram-positive Staphylococcus aureus (S. aureus, ATCC 29213) using previously developed 'Touch Test Method' [10]. Bacteria culture were diluted in $0.9 \% \mathrm{NaCl}$ to obtain a bacterial suspension equal to $0.5 \mathrm{McF}$ arland standard (approximately $1.5 \times 10^{8}$ colony-forming units [CFU]/mL). A $50 \mu \mathrm{L}$ bacterial suspension was pipetted onto the samples. Samples were then incubated at room temperature (RT) for $24 \mathrm{~h}$ in an empty Petri dish. After incubation, viable bacteria from the sample surface were replicated by pressing the sample on top of a blood agar plate (tryptic soy agar W/5\% SB (II); BD, Franklin Lakes, NJ, USA) for $30 \mathrm{~s}$. Blood agar plates were then incubated at $+37^{\circ} \mathrm{C}$ and the CFUs was determined on the next day.

\section{Results}

The surface temperature on the paper immediately after the flame deposition was approximately $40-60^{\circ} \mathrm{C}$, although the maximum temperature in the LFS flame is above $2000{ }^{\circ} \mathrm{C}$. The surface temperature depends on, and can be controlled by the speed at which the sample passes through the flame, the distance between flame nozzle and the substrate, the number of passes through the sweeps, and the heat capacity of the surface being coated. After the silver nanoparticle LFS deposition, a greyish color change was induced onto the surface of the samples depending on the number of flame passes. However, a reference sample that passes $30 \mathrm{X}$ through a flame without silver precursor did not have any observable color change in the sample surface indicating that the color change is due to the deposition of silver nanoparticles. Since LFS produces nanoparticles by pyrolysis, it is expected that the heat from the flame causes a (partial) melting of the polymer surface, especially if the glass transition temperature is lower than the temperature of the flame at the sample surface. This potentially enhances the 
adherence and embedding of nanoparticles into the polymer coating layer. Ideally, a partial embedding into the coating layer is preferred since this will improve adhesion and make nanoparticles readily available on the surface for antibacterial action. Embedding nanoparticles a few nanometers below the surface may also have the same effect. The results presented subsequently describe the embedding and its effect on antibacterial properties.

\subsection{Surface characterization}

\subsubsection{SEM image analysis}

SEM imaging showed that nanoparticles are homogeneously distributed on the substrates as seen in Fig. 2. It is also clear that the amount of nanoparticles on a surface depended on the number of passes through the flame. Larger number of flame passes (30X) produced more nanoparticles on the surface compared to less flame passes
(1X). The images show that this is true for both paper samples (PE \& PET). Particle morphology appears spherical [3]. The average size increased slightly with the number of flame passes, which can be a result of particle-particle sintering due to the induced heat from the flame. Results for the average particle sizes were about $22 \mathrm{~nm}, 27 \mathrm{~nm}$, and $32 \mathrm{~nm}$ for $1 \mathrm{X}, 10 \mathrm{X}$, and 20X, respectively. About $70-80 \%$ of particles on the surface had size between 10 and $35 \mathrm{~nm}$ and the maximum particle size was around $100 \mathrm{~nm}$. PE is a softer polymer, whereas PET provides a comparatively harder surface for nanoparticle deposition with glass transition temperatures of $-110^{\circ} \mathrm{C}$ and $78^{\circ} \mathrm{C}$, respectively.

For the same number of passes through the flame (e.g. $5 X)$, the SEM images show similar distribution and surface characteristics for both samples. At the same time, smaller nanoparticles are observed on the surface and these appear to have a lower contrast. This may suggest that particles are slightly further away from the surface. Considering that the particles are estimated to be spherical
Fig. 2 SEM images showing silver nanoparticles as bright spots on PE and PET coated surfaces. The labels indicate the polymer surface type (PE/PET) and the number of passes through the LFS flame (5X/10X/30X)
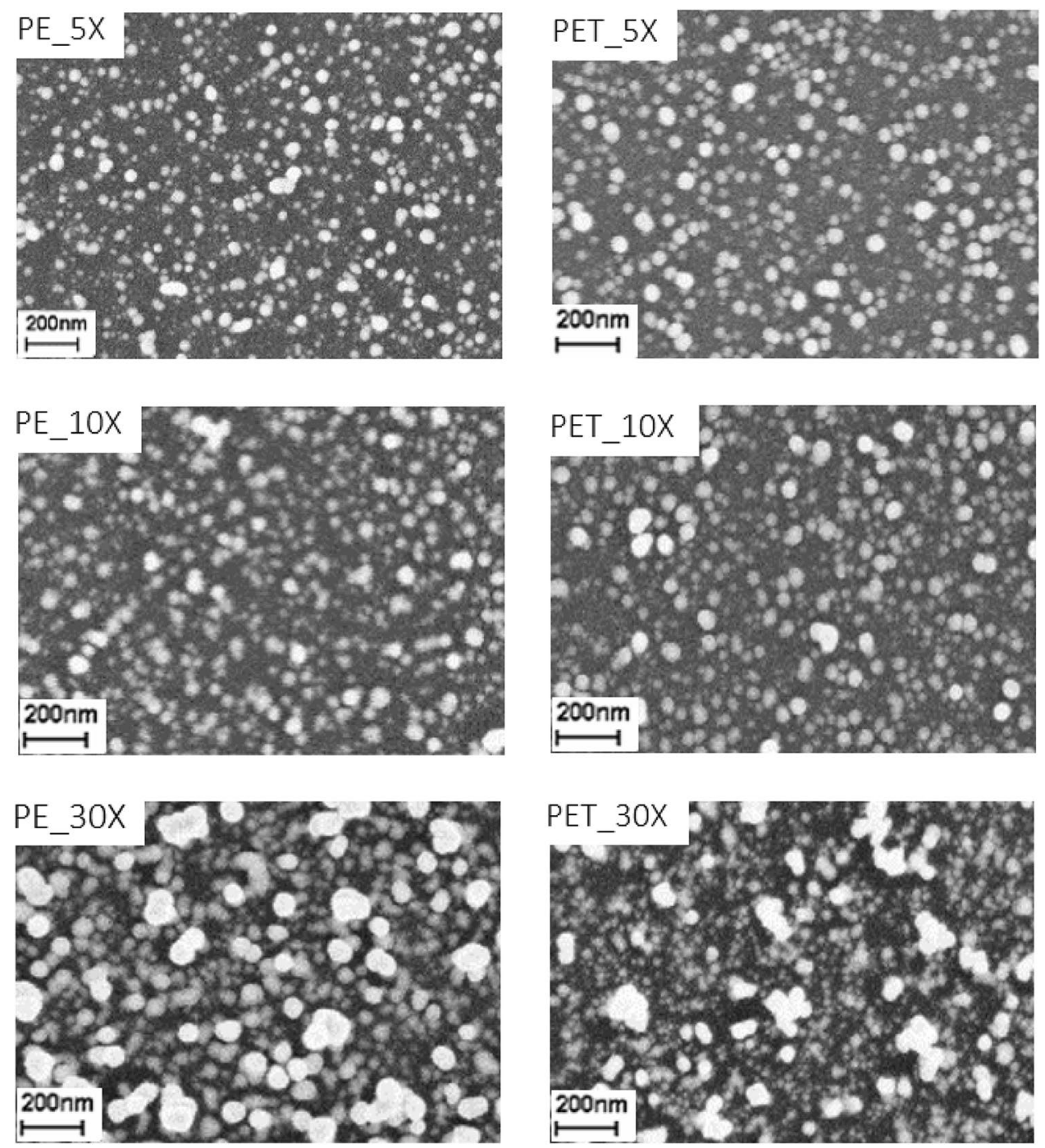
with diameter of about $30 \mathrm{~nm}$ on the surface, low contrast particles could be embedded below the coating as a result of heating that resulted from increasing the number of flame passes.

\subsubsection{AFM surface analysis}

Surface analysis by AFM was a comparison of height, phase and stiffness measurements (Figs. 3, 4). A comparison of the reference $P E$ and PE_10X samples show significant differences in the surface topography. Waviness and the absence of nanoparticles was clearly observed in reference sample. AFM images of PE_10X samples showed nanoparticles on the surface that appeared spherical, similar to observations in SEM images. The maximum height after processing varied for all samples depending on the residual waviness in the sample surface. Figure 3 shows clearly the stiffness contrast between the soft polymer surface and the relatively harder silver nanoparticles. A maximum stiffness of $2.5 \mathrm{GPa}$, was recorded for the nanoparticles whereas the reference PE without nanoparticles yielded a stiffness of about $1 \mathrm{GPa}$. Figure 3 compares the height and stiffness images from the same surface location. Some particles are only visible in the stiffness image, i.e. these particles give rise to only a very weak if any height contrast in the topograph. This observation suggests that such silver nanoparticles were embedded below the polymer surface. These embedded nanoparticles (partially or fully) still contribute to the mechanical contrast even if being coated by a polymer layer, and appear only as a gentle sloping in the height profile.

A similar kind of effect was seen in Fig. 4, which shows a phase image corresponding to the height image at a particular location. Certain nanoparticles appear distinctly in the phase image, but are not observed in the height image. This indicates that such particles were fully covered by the polymer coating and therefore contribute to the height profile by a lesser extent. However, the change in mechanical properties due to embedding is clearly observed in the phase image. A line profile at the marked locations in Fig. $4 a$, b show two clear peaks representing particles in the phase image that are weakly observed in the height image. This comparison of line profiles at the same locations between 0.04 and $0.08 \mu \mathrm{m}$ confirms the presence of an embedded nanoparticle. The "Appendix" shows full size AFM images from which the line profiles are
Fig. 3 AFM images showing the result from peak force measurements. The height and the stiffness images after image processing are shown for reference PE without silver nanoparticles in $(\mathbf{a}, \mathbf{b})$, and for PE_10X sample in $(\mathbf{c}, \mathbf{d})$
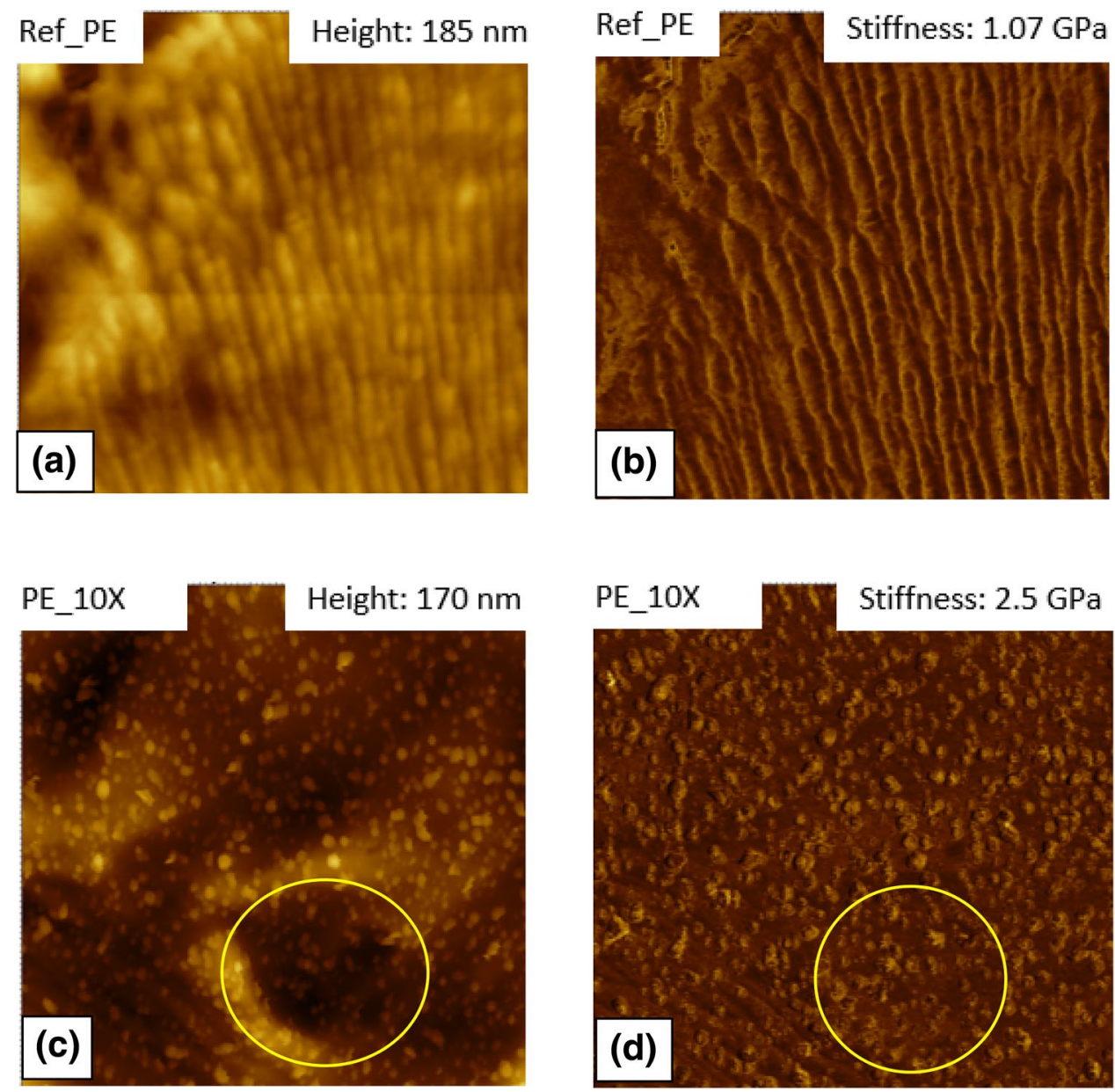

SN Applied Sciences A SPRINGer NATURE journal 

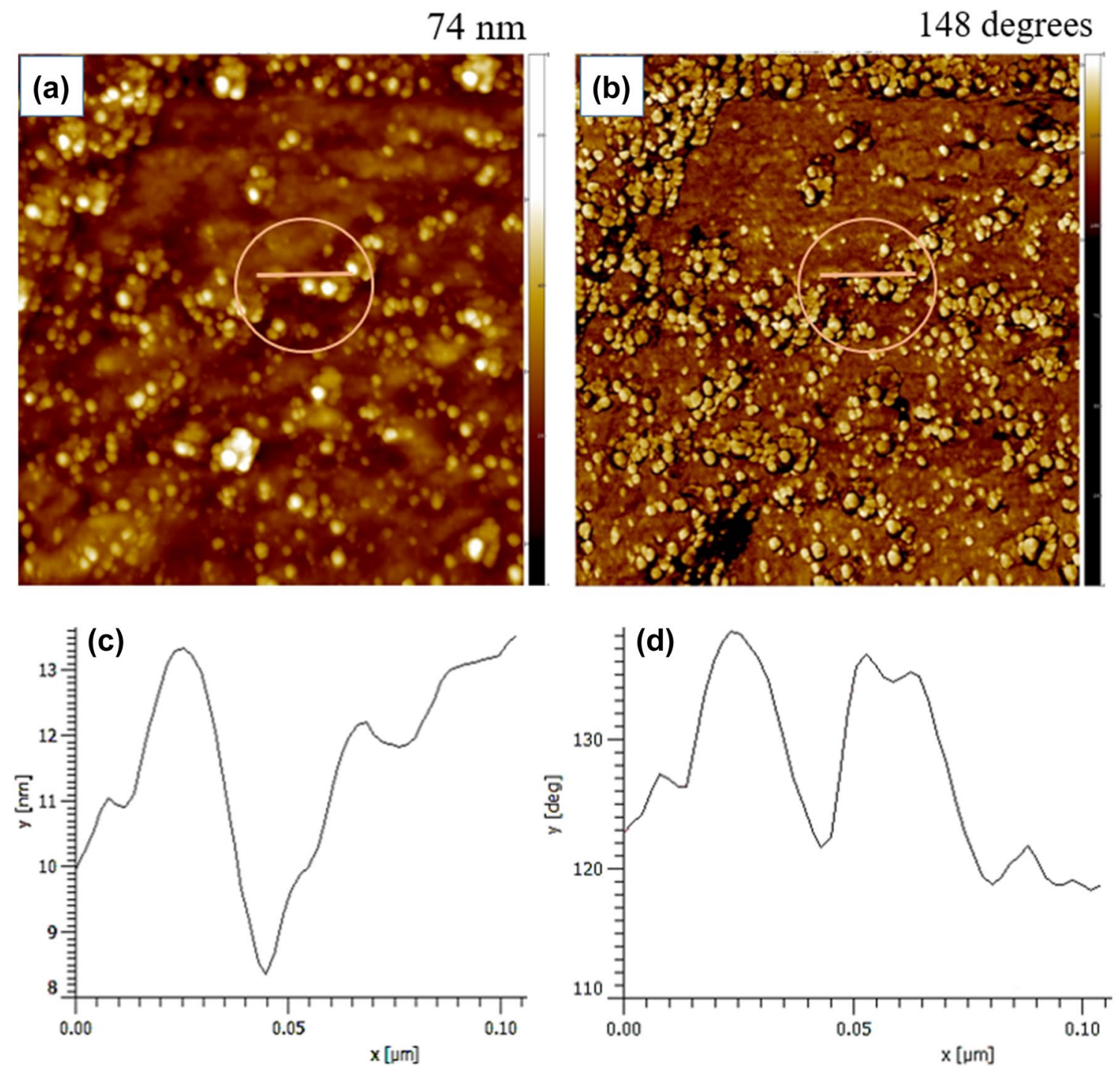

Fig. 4 AFM topographical and phase images of PE_10X showing the height image (a) and the phase image (b). The marked regions show nanoparticles that are not clearly visible in the height image, but visible in phase image. The line profiles showing embedding

are shown in (c, d) corresponding to the height and phase image respectively. The line profiles are obtained from the same coordinates in both phase and topography image

obtained. Different scenarios that describe nanoparticle embedding and the observations made in line profile of the phase and height images are given in Table 1.

\subsubsection{Focused ion beam (FIB) cross-sectional imaging}

Results from FIB-SEM imaging, which enables observation of nanoparticles from sample cross-sections, are shown in Fig. 5. The incision on the sample surface showing the cross-section is shown in (a), and a magnification of the interface between the platinum coating and the polymer coating layer in (b). A few embedded nanoparticles are visible in the polymer layer, right below the platinum coating.
The estimated maximum depth of embedding is about $30 \mathrm{~nm}$. After cross-sectional imaging, surface characterization was complemented using SEM integrated within the FIB apparatus. Imaging the sample from an angle perpendicular to the surface showed similar nanoparticle-decorated surface as was seen in Fig. 2. However, a $15^{\circ}$ tilt in the imaging angle of the surface gave a different perspective of the particle distribution as shown in Fig. 6 . The tilted image confirms that some nanoparticles were partially embedded within the coating layer. Here, the embedding and partial embedding is attributed to the thermomechanical deformation of the coating layer resulting from the heat provided by the LFS process. A lower glass 
Table 1 Different embedding scenarios describing the observation made in the line profile for height and phase images

\begin{tabular}{|c|c|c|}
\hline $\begin{array}{l}\text { Theoretical cases showing no, full } \\
\text { or partial embedding }\end{array}$ & \multicolumn{2}{|c|}{$\begin{array}{l}\text { Effect observed in the line profile extracted from AFM image } \\
\text { resulting from no, full or partial embedding }\end{array}$} \\
\hline & Height image observation & Phase image observation \\
\hline $\begin{array}{l}\mathrm{PE} \\
\text { coating } \\
\text { layer }\end{array}$ & $\begin{array}{l}\text { Maximum particle size } \\
\text { observed in line profile of } \\
\text { height image }\end{array}$ & $\begin{array}{l}\text { Actual particle size observed } \\
\text { in line profile of phase image }\end{array}$ \\
\hline $\begin{array}{l}\mathrm{PE} \\
\text { coating } \\
\text { layer }\end{array}$ & $\begin{array}{l}\text { Reduced height resulting in } \\
\text { reduced particle size observed } \\
\text { in the line profile }\end{array}$ & $\begin{array}{c}\text { Phase shows approximately } \\
\text { the actual size in the line } \\
\text { profile }\end{array}$ \\
\hline $\begin{array}{l}\qquad \begin{array}{l}\text { PE } \\
\text { coating } \\
\text { layer }\end{array} \\
\text { led AgNP } \\
\text { arface }\end{array}$ & $\begin{array}{l}\text { Nothing observed in the height } \\
\text { image }\end{array}$ & $\begin{array}{l}\text { Phase confirms and shows } \\
\text { the presence of a particle } \\
\text { below the layer due to } \\
\text { mechanical difference }\end{array}$ \\
\hline Fully embedded AgNP & $\begin{array}{l}\text { Weak observation of the } \\
\text { height }\end{array}$ & $\begin{array}{c}\text { Nanoparticle observed } \\
\text { showing approximate size in } \\
\text { the line profile }\end{array}$ \\
\hline $\begin{array}{l}\text { Fully embedded AgNP } \\
\text { coating } \\
\text { layer }\end{array}$ & $\begin{array}{l}\text { No observation in height } \\
\text { image }\end{array}$ & $\begin{array}{l}\text { No significant observation in } \\
\text { the phase }\end{array}$ \\
\hline
\end{tabular}

transition temperature for PE in comparison to PET also facilitated the integration of the nanoparticles into the softened polymer surface. The softened polymer surface acted as a molten plastic that captured the nanoparticles expelled from the nozzle in the LFS coating process.
One can observe from Fig. 6 that some nanoparticles are vertically oriented on the surface forming assemblies similar to nano-pillars. The vertical orientation may have resulted from sintering of particles that settled on top of each other. This effect was more dominant in samples that had a higher number of flame passes. Further analysis of 


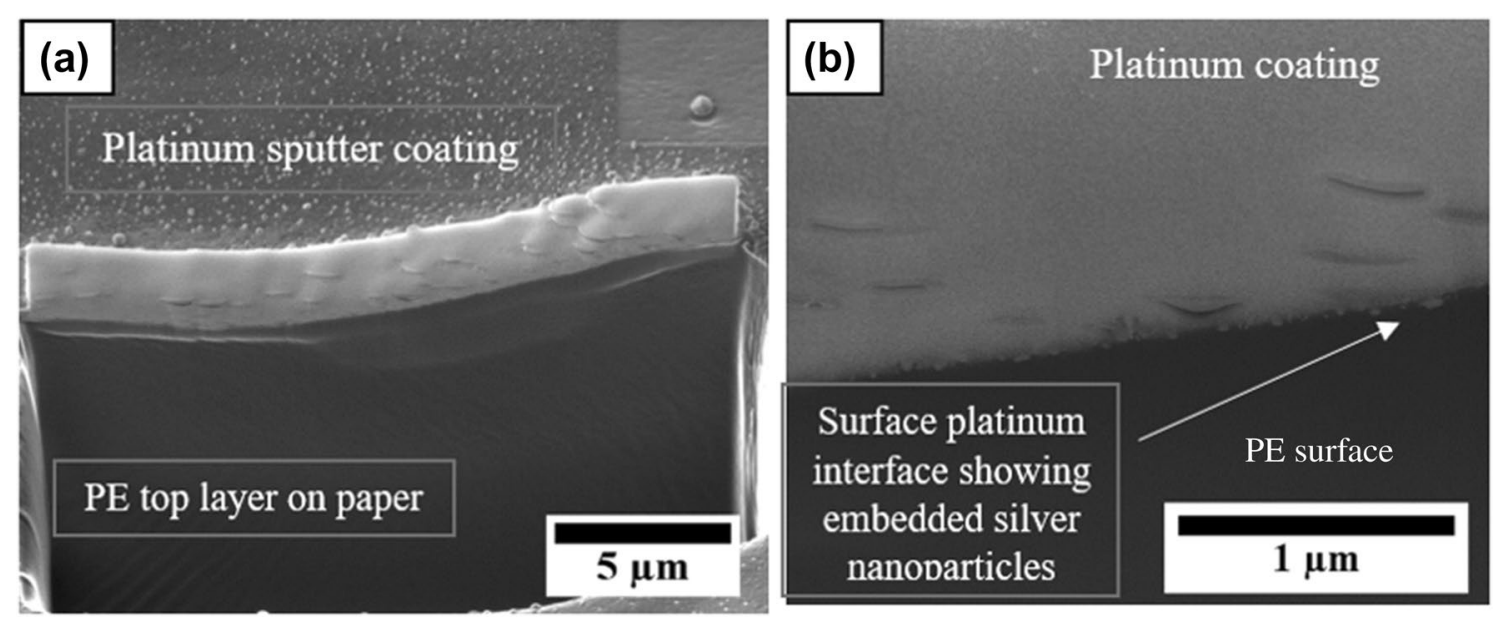

Fig. 5 Cross-section of PE_30X. The cut cross-section is shown (a) and a close-up image (b) that shows the embedding of nanoparticles in the top layer of the cross-section

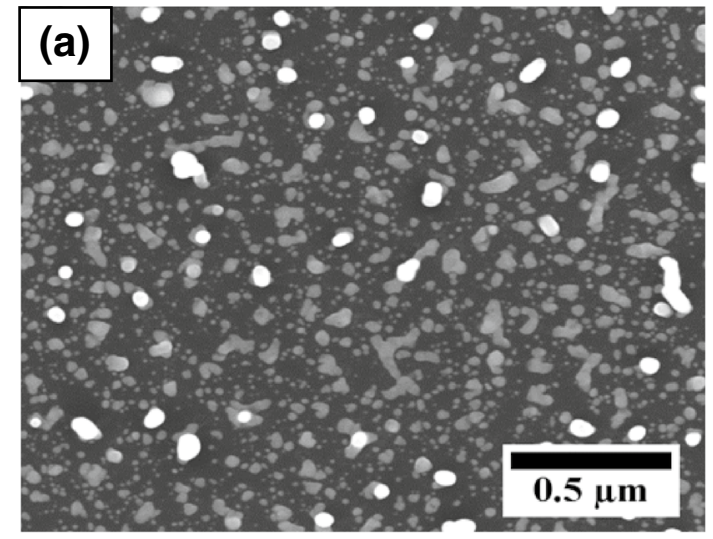

PE_30X perpendicular image

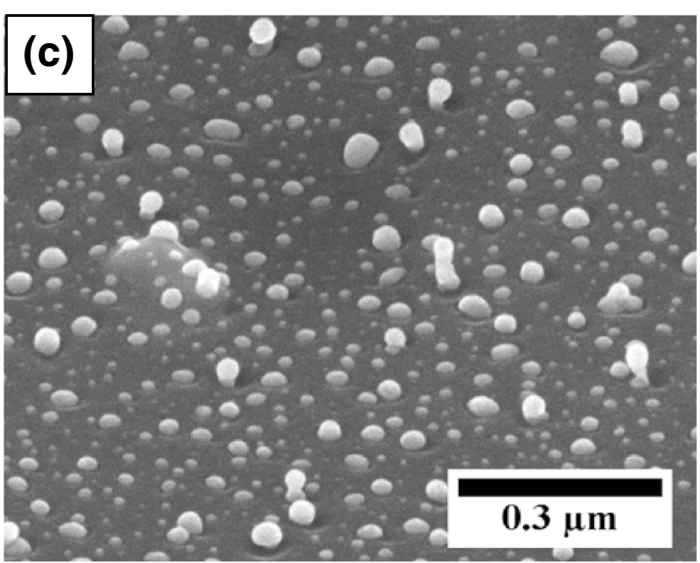

PET_30X tilted image

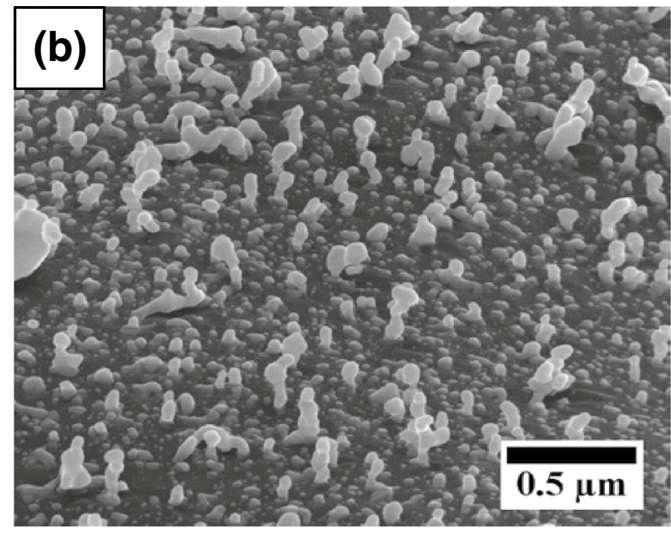

PE_30X tilted image

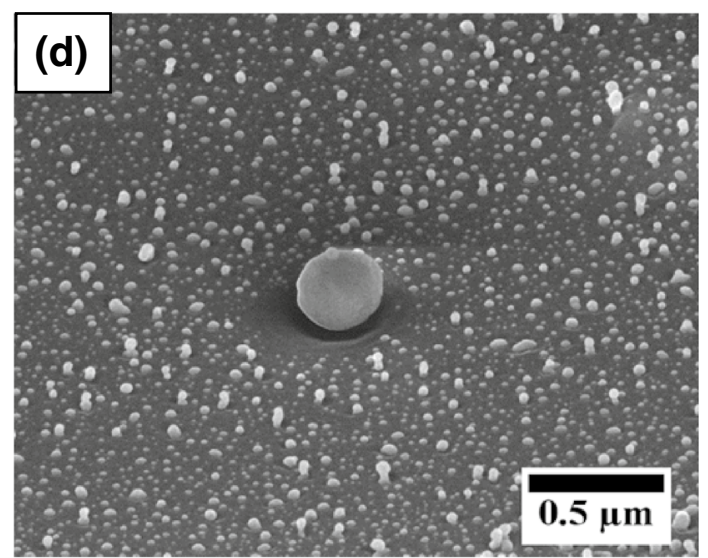

PET_30X tilted image

Fig. 6 A comparison of perpendicular surface image to tilted surface image from FIB-SEM imaging is shown in (a, b) for PE. c, d Show tilted images for PET_30X surface showing the presence of structures similar to nano-pillars 
FIB-SEM images revealed that the more nano-pillar structures were found on PE_30X in comparison to PET_30X as shown in Fig. 6. For PE_30X, particles that were embedded within the coating layer appeared to be mixed with the surface of coatings. On the other hand, particles appeared to be mostly partially embedded in PET_30X. There were isolated cases where large particles appeared to be fixed to the surface similar to a meteorite attached within a crater. These could have resulted from excessively large precursor droplets within the LFS flame.

\subsubsection{XPS analysis}

Silver nanoparticles on the surface was quantified in atomic percentage using XPS (Fig. 7). The amount of measured silver on sample surfaces increased in proportion to the number of flame passes, reaching ca. 15-20 at.\% for the $30 \mathrm{X}$ samples. Both PE and PET samples showed a

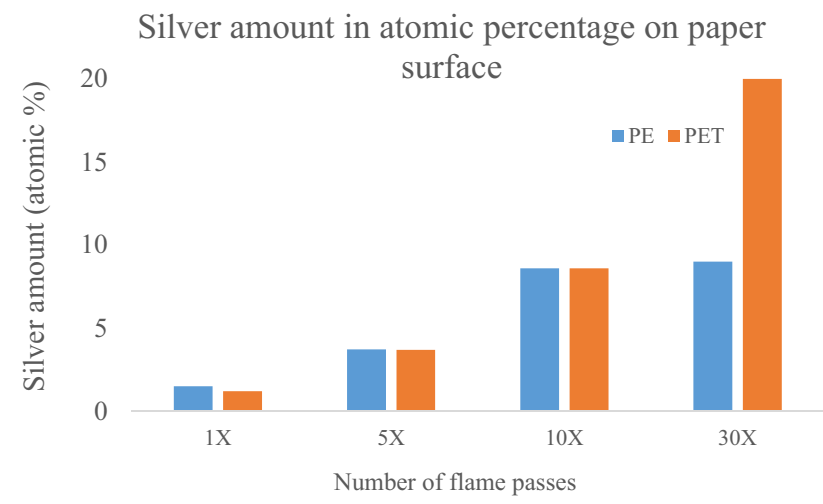

Fig. 7 Silver amount measured by XPS for increasing number of passes through the LFS flame

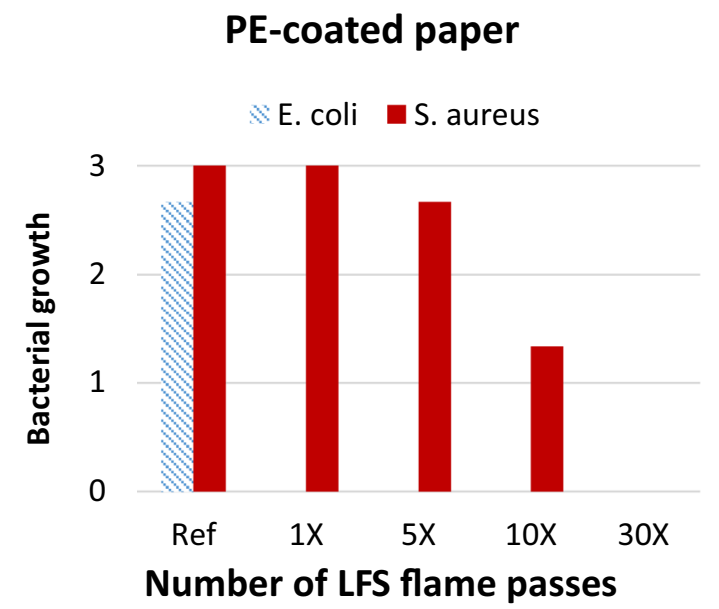

similar amounts of silver on the surface, with the exception of 30X sample, where the PE sample showed a lower silver amount. Repeated passes through the flame raised the sample surface temperature, thereby (partially) melting the polymer allowing the nanoparticles to penetrate into the surface. This suggests that for the PE_30X sample, a significant amount of nanoparticles were partially or fully embedded in the polymer surface. Since the maximum electron escape depth in XPS is ca. $10 \mathrm{~nm}$, nanoparticles beyond this depth are not detected, which could have resulted in the lower silver amount observed for PE samples. It appears that in the current experiments, the surface temperature did not rise above the glass transition temperature of PET, which is considerably higher than that of PE. It is important to note that the glass transition temperature of the polymer coating is an important parameter to be considered in the embedding process.

\subsection{Antibacterial characterization}

Our previous work confirmed that silver nanoparticle coated paper fabricated using the LFS process is antibacterial [4]. In the current study, the focus was to demonstrate nanoparticle embedding while maintaining the antibacterial effect. Nanoparticles that are embedded too deep within the coating layer may hinder the release of silver to the surface, resulting in reduced or no antibacterial effect. Bacterial growth during the testing was ranked as $0,1,2,3$, corresponding to no growth, weak growth (0-50 CFU), moderate growth (50-100 CFU), and strong growth (>100 CFU), respectively [10]. The results in Fig. 8 show that the antibacterial properties of the paper samples were maintained on the polymer coated surfaces. The mechanism of antibacterial action was not studied, but this could be a result of rapturing the cell wall or

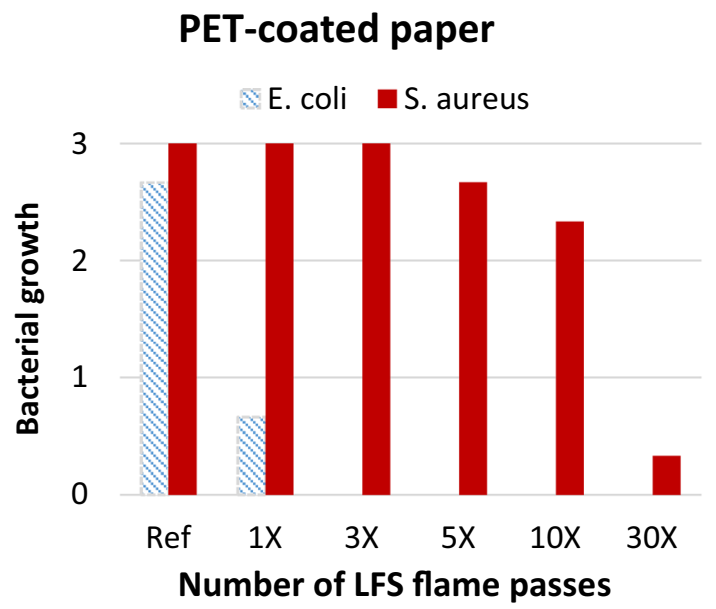

Fig. 8 Antibacterial results for paper samples as a function of the number of flame passes, using E. coli and S. aureus as test organisms 
modification of internal cell processes resulting in bacteria death, as suggested in literature [26]. From the results, it is not clear whether the silver nanoparticles have a bactericidal or bacteriostatic effect. Consequently, further studies are needed to clarify this.

Reference samples had no silver coating on the surface. Therefore, they sustained the growth of both tested bacteria, E. coli and S. aureus. Silver is clearly a more effective antibacterial agent against the gram-negative $E$. coli as compared to the gram-positive S. aureus. Only some colonies of E. coli were observed on PET-coated paper with the lowest amount of deposited nanoparticles (PET_1X). For the PE-coated paper, and for the PET-coated paper with higher silver nanoparticle deposition amounts, no bacterial growth was observed for E. coli. On the contrary, response of the gram-positive $S$. aureus to the silver nanoparticles was less pronounced. Only 30X silver deposition amounts showed considerable antibacterial effect against S. aureus for both PE and PET samples. This suggests that silver coatings may be more effective against gram-negative bacteria as compared to gram-positive bacteria. Grampositive bacteria have a thicker outer covering mainly constituted of peptidoglycan, which makes it difficult for the nanoparticles or silver ions to penetrate the cell easily. Thus, this may be the reason why silver nanoparticles deposited onto the samples at low nanoparticle amounts appeared to be ineffective against $S$. aureus. Alternatively, the silver amount may have been below the limit required to inhibit S. aureus, especially for coatings less than $30 X$.

\section{Conclusions}

A one-step flame synthesis was previously demonstrated for the fabrication of antibacterial paper. However, ensuring adhesion of nanoparticles to the surface was recognized as a challenge. Heat produced in the LFS process was used to improve nanoparticle adhesion by embedding them into the polymer layer on top of paper samples. The results suggest that embedding was more effective in PE samples due to their lower glass transition temperature when compared to PET. Nanoparticle coatings demonstrated antibacterial properties against $E$. coli, but S. aureus was resistant except for high number of flame passes. Partial or full embedding of nanoparticles did not reduce the antibacterial effect. Nanoparticle deposition was demonstrated on lab-scale using a carousel, but it can be transferred onto a roll-to-roll production line, which has previously been demonstrated for other LFS-generated nanoparticles. The study demonstrates a continuous synthesis of antibacterial paper that is uniquely capable of improving nanoparticle adhesion, thereby reducing environmental exposure.

Acknowledgements Open access funding provided by Abo Akademi University (ABO). This work was supported by the Academy of Finland under the project "Nanostructured large-area antibacterial surfaces (nLABS, Grant No. 275 475)". ER and JP wish to acknowledge the Center for Functional Materials (FunMat) at Åbo Akademi University and the Academy of Finland (Grant No. 307466) for financial support.

\section{Compliance with ethical standards}

Conflict of interest The authors declare no conflict of interest.

Open Access This article is distributed under the terms of the Creative Commons Attribution 4.0 International License (http://creativeco mmons.org/licenses/by/4.0/), which permits unrestricted use, distribution, and reproduction in any medium, provided you give appropriate credit to the original author(s) and the source, provide a link to the Creative Commons license, and indicate if changes were made.

\section{Appendix}

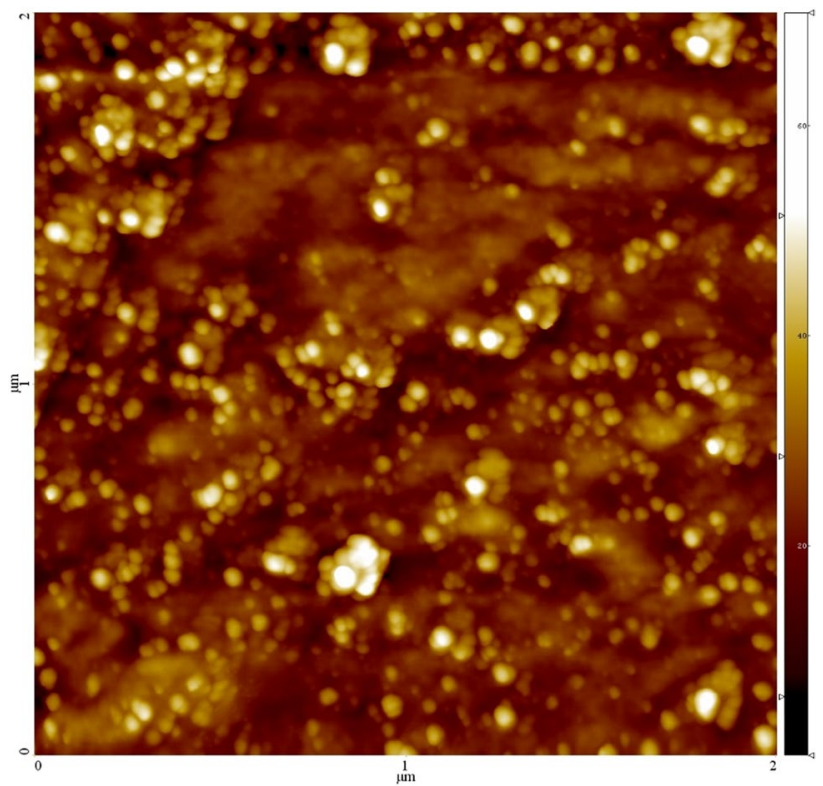

Height profile for PE_10X 


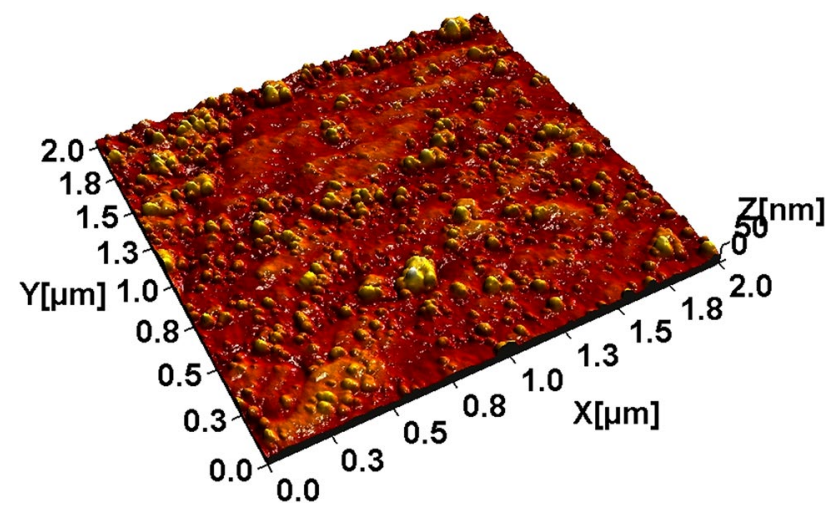

Height profile for PE_10X-3D

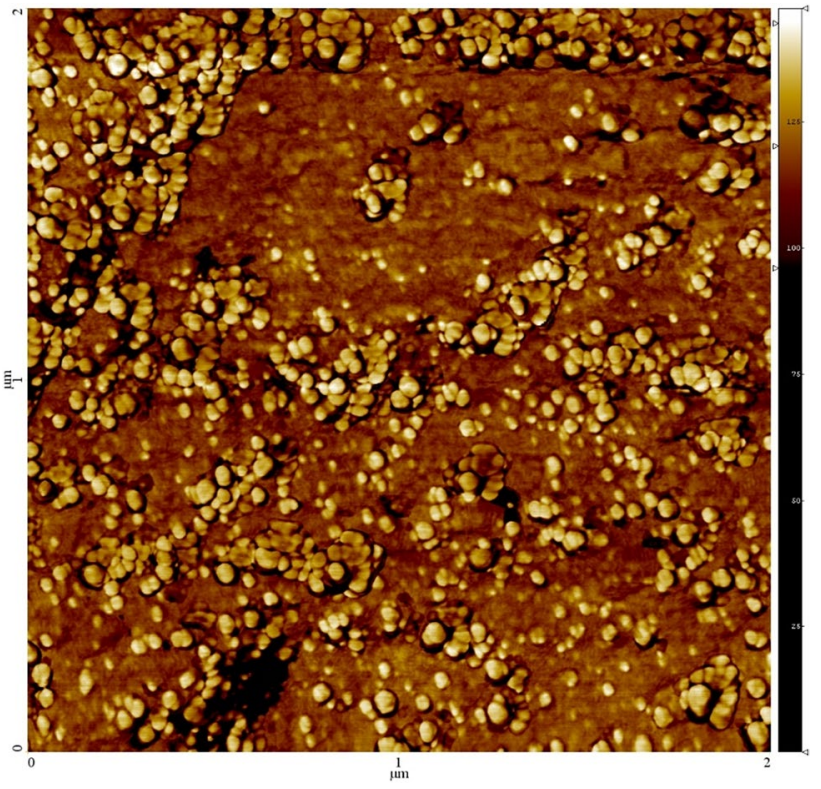

Phase profile for PE_10X using hard tapping $1500 \mathrm{mV}$

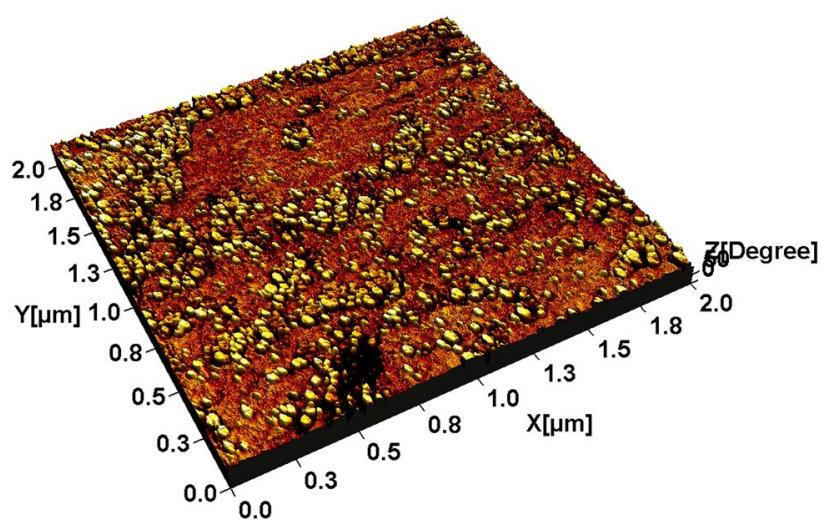

Phase profile for PE_10X using hard tapping $1500 \mathrm{mV}-3 \mathrm{D}$

See Table 1. 
The line profiles at the same location in the height and phase image for 4 different points

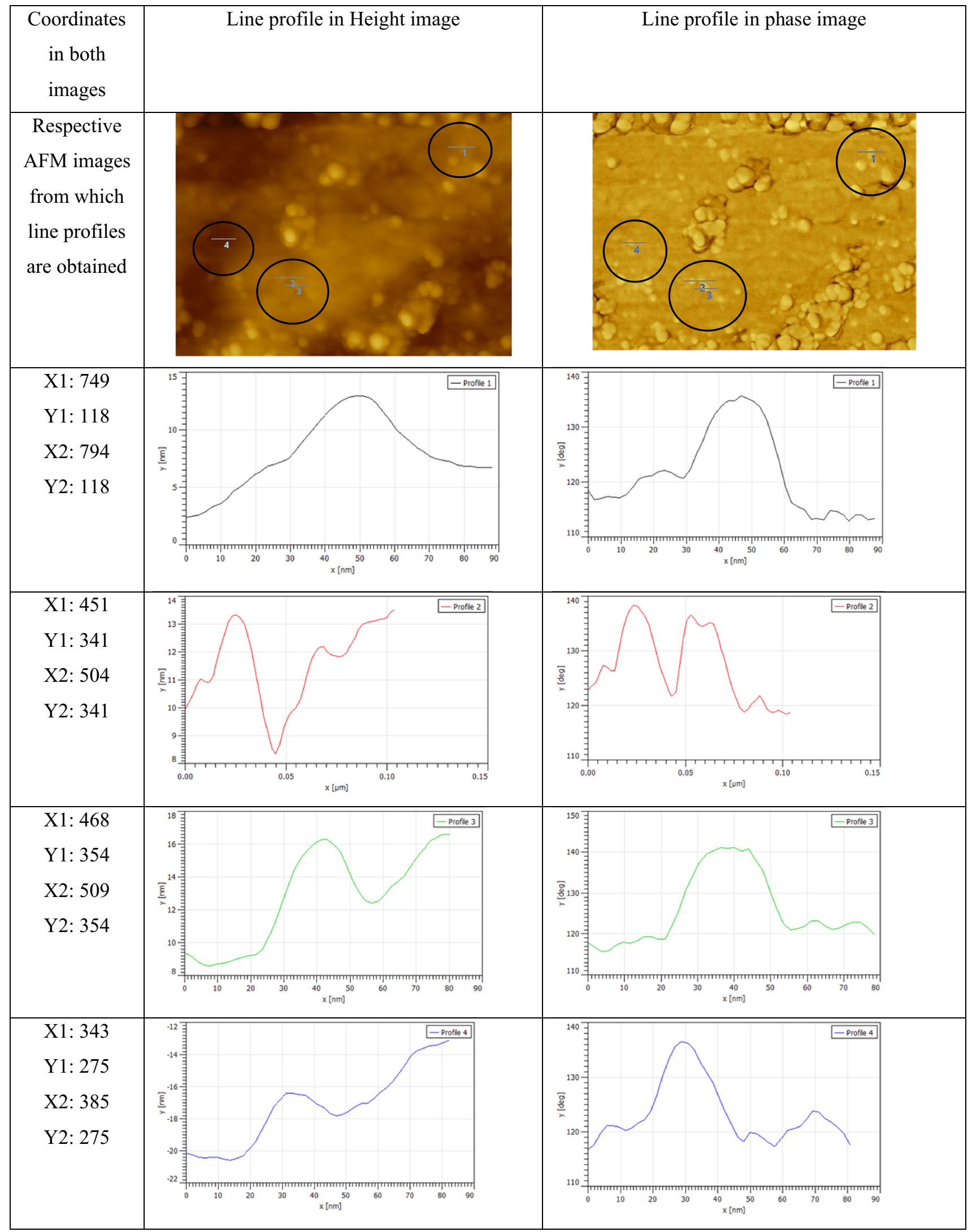




\section{References}

1. Ansari MA, Khan HM, Khan AA et al (2015) Anti-biofilm efficacy of silver nanoparticles against MRSA and MRSE isolated from wounds in a tertiary care hospital. Indian J Med Microbiol 33(1):101-109. https://doi.org/10.4103/0255-0857.148402

2. Aromaa M, Arffman A, Suhonen $\mathrm{H}$ et al (2012) Atmospheric synthesis of superhydrophobic $\mathrm{TiO}_{2}$ nanoparticle deposits in a single step using liquid flame spray. J Aerosol Sci 52:57-68. https ://doi.org/10.1016/j.jaerosci.2012.04.009

3. Brobbey KJ, Haapanen J, Gunell M et al (2017) One-step flame synthesis of silver nanoparticles for roll-to-roll production of antibacterial paper. Appl Surf Sci 420(Supplement C):558-565

4. Brobbey KJ, Haapanen J, Gunell M et al (2018) Controlled time release and leaching of silver nanoparticles using a thin immobilizing layer of aluminum oxide. Thin Solid Films 645(Supplement C):166-172

5. Dey J, Biswas K, Thapa U et al (2015) Facile synthesis of silver nanoparticles and their synergistic antibacterial activity in combination with commercial antibiotics. Bull Chem Soc Jpn 88(2):352-357. https://doi.org/10.1246/bcsj.20140255

6. Dizaj SM, Lotfipour F, Barzegar-Jalali M et al (2014) Antimicrobial activity of the metals and metal oxide nanoparticles. Mater Sci Eng C 44:278-284. https://doi.org/10.1016/j.msec.2014.08.031

7. Evans ER, Bugga P, Asthana V et al (2017) Metallic nanoparticles for cancer immunotherapy. Mater Today (Oxford, UK). Ahead of Print. https://doi.org/10.1016/j.mattod.2017.11.022

8. Fahmy A, Friedrich J, Poncin-Epaillard F et al (2016) Plasma polymerized allyl alcohol $/ \mathrm{O}_{2}$ thin films embedded with silver nanoparticles. Thin Solid Films 616(Supplement C):339-347

9. Friedman M (2015) Antibiotic-resistant bacteria: prevalence in food and inactivation by food-compatible compounds and plant extracts. J Agric Food Chem 63(15):3805-3822. https://doi. org/10.1021/acs.jafc.5b00778

10. Gunell M, Haapanen J, Brobbey KJ et al (2017) Antimicrobial characterization of silver nanoparticle-coated surfaces by"touch test" method. Nanotechnol Sci Appl 10:137-145. https://doi. org/10.2147/NSA.S139505

11. Gyawali R, Ibrahim SA (2014) Natural products as antimicrobial agents. Food Control 46:412-429. https://doi.org/10.1016/j. foodcont.2014.05.047

12. He R, Ren F, Chen F (2017) Embedded silver nanoparticles in KTP crystal produced by ion implantation. Mater Lett 193(Supplement C):158-160

13. Huang J, Wang $\mathrm{H}$, Zhang K (2014) Modification of PES membrane with $\mathrm{Ag}-\mathrm{SiO}_{2}$ : reduction of biofouling and improvement of filtration performance. Desalination 336:8-17. https://doi. org/10.1016/j.desal.2013.12.032

14. Ju-Nam Y, Lead J (2016) Properties, sources, pathways, and fate of nanoparticles in the environment. In: Anonymous. Wiley, pp 93-117

15. Lin C, Yang S, Gu J et al (2017) The acute toxic effects of silver nanoparticles on myocardial transmembrane potential, INa and IK1 channels and heart rhythm in mice. Nanotoxicology 11(6):827-837. https://doi.org/10.1080/17435390.2017.13670 47

16. Liu H, Lu M, Zhu M et al (2018) Continuous biosynthesis of silver nanoparticles in a hydrodynamic cavitation device and modeling of the process by numerical simulation strategy. J Nanopart Res 20(9):233. https://doi.org/10.1007/s11051-018-4330-3

17. Maior MC, Dobrota C (2013) Natural compounds with important medical potential found in Helleborus sp. Cent Eur J Biol 8(3):272-285. https://doi.org/10.2478/s11535-013-0129-x

18. Mäkelä JM, Aromaa M, Teisala H et al (2011) Nanoparticle deposition from liquid flame spray onto moving roll-to-roll paperboard material. Aerosol Sci Technol 45(7):827-837. https ://doi.org/10.1080/02786826.2011.566292

19. Mäkelä JM, Hellstén S, Silvonen J et al (2006) Collection of liquid flame spray generated $\mathrm{TiO}_{2}$ nanoparticles on stainless steel surface. Mater Lett 60(4):530-534. https://doi.org/10.1016/j.matle t.2005.09.062

20. Morris AS, Salem AK (2017) Surface engineered nanoparticles: considerations for biomedical applications. Adv Eng Mater 19(11):1700302. https://doi.org/10.1002/adem.201700302

21. Moulder JF, Stickle WF, Sobol PE et al (1992) Handbook of X-ray photoelectron spectroscopy, Eden Prairie. Perkin-Elmer Corporation, Physical Electronics Division

22. Nguyen TAT, Dang VP, Nguyen ND et al (2014) Bactericidal activity and silver release of porous ceramic candle filter prepared by sintering silica with silver nanoparticles/zeolite for water disinfection. Adv Nat Sci Nanosci Nanotechnol 5(3):035001/1035001/6. https://doi.org/10.1088/2043-6262/5/3/035001

23. Pimenoff JA, Hovinen AK, Rajala MJ (2009) Nanostructured coatings by liquid flame spraying. Thin Solid Films 517(10):30573060. https://doi.org/10.1016/j.tsf.2008.11.082

24. Pugliara A, Makasheva K, Despax B et al (2016) Assessing bioavailable silver released from silver nanoparticles embedded in silica layers using the green algae Chlamydomonas reinhardtii as bio-sensors. Sci Total Environ 565(Supplement C):863-871

25. Pulit-Prociak J, Stoklosa K, Banach M (2015) Nanosilver products and toxicity. Environ Chem Lett 13(1):59-68. https://doi. org/10.1007/s10311-014-0490-2

26. Rani Reena, Sharma Dushyant, Chaturvedi Monika, Yadav JP (2017) Green synthesis, characterization and antibacterial activity of silver nanoparticles of endophytic fungi Aspergillus terreus. J Nanomed Nanotechnol 8(4):1-8. https://doi. org/10.4172/2157-7439.1000457

27. Roy B, Bharali P, Konwar BK et al (2013) Silver-embedded modified hyperbranched epoxy/clay nanocomposites as antibacterial materials. Biores Technol 127(Supplement C):175-180

28. Saeb ATM, Alshammari AS, Al-Brahim H et al (2014) Production of silver nanoparticles with strong and stable antimicrobial activity against highly pathogenic and multidrug resistant bacteria. Sci World J. https://doi.org/10.1155/2014/704708

29. Senarathna KGC, Rajapakse RMG, Bandara HMN et al (2014) Synthesis and characterization of polyaniline-silver-montmorillonite clay nanocomposite: application in fuel cell. In: Anonymous American Chemical Society, p POLY-463

30. Shokeen P, Jain A, Gupta V et al (2017) Multilayer silver nanoparticles embedded in graded-index dielectric layers. Opt Mater 66(Supplement C):29-34

31. Solomon MM, Gerengi H, Umoren SA (2017) Carboxymethyl cellulose/silver nanoparticles composite: synthesis, characterization and application as a benign corrosion inhibitor for St37 Steel in $15 \% \mathrm{H}_{2} \mathrm{SO}_{4}$ medium. ACS Appl Mater Interfaces 9(7):6376-6389

32. Som C, Wick $P$, Krug $H$ et al (2011) Environmental and health effects of nanomaterials in nanotextiles and façade coatings. Environ Int 37(6):1131-1142. https://doi.org/10.1016/j.envin t.2011.02.013

33. Stepien M, Saarinen JJ, Teisala $\mathrm{H}$ et al (2012) Surface chemical analysis of photocatalytic wettability conversion of $\mathrm{TiO}_{2}$ nanoparticle coating. Surf Coat Technol 208:73-79. https://doi. org/10.1016/j.surfcoat.2012.08.008

34. Stepien M, Saarinen JJ, Teisala H et al (2012) Surface chemical characterization of nanoparticle coated paperboard. Appl Surf Sci 258(7):3119-3125. https://doi.org/10.1016/j.apsus c. 2011.11 .048

35. Tankhiwale R, Bajpai SK (2009) Graft copolymerization onto cellulose-based filter paper and its further development as 
silver nanoparticles loaded antibacterial food-packaging material. Colloids Surf B Biointerfaces 69(2):164-168. https://doi. org/10.1016/j.colsurfb.2008.11.004

36. Taylor PK, Yeung ATY, Hancock REW (2014) Antibiotic resistance in Pseudomonas aeruginosa biofilms: towards the development of novel anti-biofilm therapies. J Biotechnol 191:121-130. https ://doi.org/10.1016/j.jbiotec.2014.09.003

37. Tenover FC, McGowan JE Jr (2008) Antimicrobial resistance. In: Heggenhougen HK (ed) International encyclopedia of public health. Academic Press, Oxford, pp 211-219

38. Vazquez-Munoz R, Borrego B, Juarez-Moreno K et al (2017) Toxicity of silver nanoparticles in biological systems: does the complexity of biological systems matter? Toxicol Lett 276:11-20. https://doi.org/10.1016/j.toxlet.2017.05.007

39. Wadke P, Chhabra R, Jain R et al (2017) Silver-embedded starchbased nanofibrous mats for soft tissue engineering. Surf Interfaces 8(Supplement C):137-146

40. Whiteley CM, Dalla Valle M, Jones KC et al (2013) Challenges in assessing release, exposure and fate of silver nanoparticles within the UK environment. Environ Sci Process Impacts 15(11):2050-2058. https://doi.org/10.1039/c3em00226h

41. Xu J, Xu N, Zhou T et al (2016) Polydopamine coatings embedded with silver nanoparticles on nanostructured titania for longlasting antibacterial effect. Surf Coat Technol 6:2. https://doi. org/10.1016/j.surfcoat.2016.10.065

42. Zboril R, Soukupova J (2012) Immobilization method of silver nanoparticles to solid substrates. Univerzita Palackeho v Olomouci, Czech Rep. CZ303502B6, 10/24

43. Zhao G, Chen J, Huang Y et al (2015) Novel antibacterial hybrid materials based on polyvinyl alcohol and mercaptopropyltriethoxysilane with embedded silver nanoparticles (PVA/AgNps/ MPTES). C R Chim 18(5):586-592

44. Zheng X, Wang J, Chen Y et al (2018) Comprehensive analysis of transcriptional and proteomic profiling reveals silver nanoparticles-induced toxicity to bacterial denitrification. J Hazard Mater 344:291-298. https://doi.org/10.1016/j.jhazmat.2017.10.028 